\title{
Using Impedance Spectroscopy to Assess the Viability of the Rapid Chloride Test for Determining Concrete Conductivity
}

K. A. Snyder, C. Ferraris, N. S. Martys, and E. J. Garboczi

National Institute of Standards and Technology, Gaithersburg, MD 20899-8120

kenneth.snyder@nist.gov chiara.ferraris@nist.gov nicos.martys@nist.gov edward.garboczi@nist.gov
The suitability of using the initial current from the rapid chloride test (ASTM C 1202) to determine specimen conductivity is tested using impedance spectroscopy with a frequency spectrum of $10 \mathrm{~Hz}$ to 1 MHz. The specimen conductivity has an analytical relationship to specimen diffusivity and so is a useful quantity in service life prediction. Measurements made on specimens of different lengths indicate that the total charge passed during the six hour conduction test carried out according to ASTM C 1202 is not a direct measure of specimen conductivity. Further, ohmic heating during the 6 hour test makes it nearly impossible to directly measure any specimen transport property from the results. The total charge passed during the 6 hour conduction test is, therefore, not a reliable quantity for service life prediction. Results indicate that the direct current (dc) measurement of resistance using a voltage of $60 \mathrm{~V}$ is sufficient to overwhelm polarization effects, thereby yielding an accurate estimate of the true specimen conductivity. Impedance spectroscopy measurements also indicate that corrosion may form on the brass electrodes, adding bias to a conductivity estimate based upon a dc measurement.

Key words: building technology; concrete; inductivity; diffusivity; impedance spectroscopy; rapid chloride test.

Accepted: March 14, 2000

Available online: http://www.nist.gov/jres

\section{Introduction}

There has been considerable research interest in studies of diffusive ion transport through the saturated pore space of portland cement paste. Measurements of conductivity have provided a useful insight into characterizing relevant transport properties [1-8]. This effort has been motivated by the direct relationship between the concrete conductivity and both the steel reinforcement corrosion rate and the ion diffusivity. The concrete conductivity is directly proportional to the reinforcement corrosion current, and it can also be related to the ion diffusivity through the Nernst-Einstein equation for electrical potential gradients or the Nernst-Plank equation for both electrical and chemical potential gradients (see Ref. [9], Chap. 4). Therefore, concrete conductivity can be an important transport property in determining concrete service life in corrosive environments.

Both the American Association of State Highway and Transportation Officials (AASHTO) and the American Society for Testing and Materials (ASTM) have a standardized test of electrical conduction through concrete, referred to here as the rapid chloride test (RCT). This test measures the cumulative electrical charge passing through a specimen subjected to a direct current (dc) voltage of $60 \mathrm{~V}$ over a period of $6 \mathrm{~h}$. However, changes in the pore fluid conductivity due to ohmic heating $[10,11]$, and changes in the microstructure due to elec- 
tromigration [12] prevent the standardized six hour test from yielding a direct measure of specimen dc conductivity and diffusivity.

The work described herein explores whether specimen diffusivity can be determined from some other aspect of the RCT. Experiments have been performed elsewhere that demonstrate the direct relationship between specimen conductivity and diffusivity [13-15]. Experiments have also been performed which purport to demonstrate a causal relationship between measurements of diffusivity and either the total charge passed or the initial current using the RCT cell [16-22]. However, no direct relationships between parameters of the RCT and diffusivity have been proven. Therefore, a means to accurately determine specimen conductivity from RCT data would be a crucial step towards establishing a relationship between RCT data and specimen diffusivity.

Accurate measurements of specimen conductivity can be made using the experimental techniques of impedance spectroscopy (IS). Using an alternating current $(\mathrm{ac})$ that varies over a wide range of frequencies, effects such as electrode polarization and ion transfer can be eliminated, yielding the true specimen resistance. The specimen conductivity may then be calculated from the measured resistance and a knowledge of the specimen geometry. However, under certain conditions, these electrode effects may be negligible. There is a small range of frequencies over which the electrode effects have an insignificant contribution to the overall conductivity, leading a number of investigators to report specimen impedance at a fixed frequency. Further, it may be possible to estimate specimen conductivity in a situation where the electrode effects are relatively small compared to the applied potential. Experiments have shown that the combined electrode effects generate a voltage drop of less than $2 \mathrm{~V}[3,23]$. Therefore, one may conjecture that if a specimen is subjected to a dc electrical potential of $60 \mathrm{~V}$, and if the combined electrode effects generate a negligible voltage drop, the specimen conductivity calculated from the resultant dc current may be sufficiently accurate for most purposes.

Reported herein are the results from IS measurements performed on specimens just prior to the application of the $60 \mathrm{~V}$ specified by the RCT. A frequency spectrum of $10 \mathrm{~Hz}$ to $1 \mathrm{MHz}$ was used to determine the true specimen resistance, from which the conductivity was calculated. The RCT setup used here recorded the current at $60 \mathrm{~s}$ intervals, including the instantaneous initial current, until the completed test at $6 \mathrm{~h}$. Results show that the initial RCT current can be used to directly and accurately determine the specimen conductivity. Implications of this result for possible future "rapid" tests are discussed.

\section{Impedance Spectroscopy}

Specimen conductivity can be most accurately determined using the principles of IS [24]. In an IS measurement, the specimen is subjected to an ac voltage over a range of frequencies, and the phase (with respect to the applied potential) and amplitude of the current are measured at each frequency. In order to interpret the IS results, the impedance response of a specimen is approximated by an equivalent circuit. The components of the circuit have a physical correspondence to components of the specimen. For metal electrodes against a saturated porous material composed of an insulating solid framework and a pore space filled with electrolyte, the impedance response can be approximated by an equivalent circuit composed of resistances $R$ and $C$ [24,25]. A simple equivalent circuit for the RCT is shown in Fig. 1. The subscripts "E" and "B" represent the electrode and the bulk components, respectively. The term bulk represents the porous solid and electrolyte pore solution composite, and is interchangeable in meaning with specimen in this context. The resistance $R_{\mathrm{B}}$ in Fig. 1 represents the dc resistance of the RCT specimen. The capacitance $C_{\mathrm{B}}$ represents the specimen capacitance due to the electrolyte in the pore space. The electrode elements $R_{\mathrm{E}}$ and $C_{\mathrm{E}}$ represent the impedance response of the electrodes due to polarization and charging effects.

The equivalent circuit in Fig. 1 is composed of parallel resistors and capacitors connected in series. The impedance of a resistor $Z_{\mathrm{R}}$ and a capacitor $Z_{\mathrm{C}}$ are complex quantities $(\mathrm{i}=\sqrt{-1})$ that are parametrized by the ac angular frequency $\omega[26]$ :

$$
Z_{\mathrm{R}}=R \quad Z_{\mathrm{C}}=\frac{1}{\mathrm{i} \omega C}
$$

The complex nature of the impedance corresponds to a phase difference between the current and the voltage through these devices; a resistor, having a pure real impedance, does not contribute to a change in the phase.

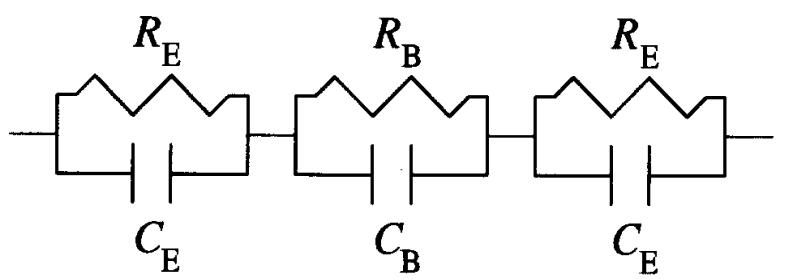

Fig. 1. A simplified equivalent circuit used to model the electrode and bulk impedance of the rapid chloride test (RCT) cell. The electrode resistance $R_{\mathrm{E}}$ and electrode capacitance $C_{\mathrm{E}}$ characterize the electrodeelectrolyte junction. The bulk resistance $R_{\mathrm{B}}$ and bulk capacitance $C_{\mathrm{B}}$ characterize the saturated concrete specimen. 
The circuit in Fig. 1 can exhibit both a capacitive and resistive response. For some values of $\omega$, the current and the voltage are nearly in phase. In this case, the impedance has no complex component, and the entire system behaves like a purely resistive element. These values of $\omega$ for which the system is purely resistive can be determined from the total impedance of the equivalent circuit in Fig. 1:

$$
\begin{gathered}
Z(\omega)=\left(\frac{2 R_{\mathrm{E}}}{1+\left(\frac{w}{w_{\mathrm{E}}}\right)^{2}}+\frac{R_{\mathrm{B}}}{1+\left(\frac{w}{w_{\mathrm{B}}}\right)^{2}}\right) \\
-\mathrm{i}\left(\frac{2 R_{\mathrm{E}}\left(\frac{w}{w_{\mathrm{E}}}\right)}{1+\left(\frac{w}{w_{\mathrm{E}}}\right)^{2}}+\frac{R_{\mathrm{B}}\left(\frac{w}{w_{\mathrm{B}}}\right)}{1+\left(\frac{w}{w_{\mathrm{B}}}\right)^{2}}\right)=Z^{\prime}(\omega)+\mathrm{i} Z^{\prime \prime}(\omega)
\end{gathered}
$$

The quantities $Z^{\prime}$ and $Z^{\prime \prime}$ represent the real and imaginary components of $Z$, respectively. The constants $\omega_{\mathrm{E}}$ and $\omega_{\mathrm{B}}$ are equal to $\left(R_{\mathrm{E}} C_{\mathrm{E}}\right)^{-1}$ and $\left(R_{\mathrm{B}} C_{\mathrm{B}}\right)^{-1}$, respectively, and are of the same dimension as $\omega$ (i.e., have the same unit). In a system like saturated concrete, the quantity $\omega_{\mathrm{E}}$ may be several orders of magnitude smaller than $\omega_{\mathrm{B}}$ $\left(\omega_{\mathrm{E}} \ll \omega_{\mathrm{B}}\right)$. Given this information, there are three ranges of values for $\omega$ that are of interest:

$$
\begin{aligned}
& Z(w \rightarrow 0)=2 R_{\mathrm{E}}+R_{\mathrm{B}} \\
& Z(w \rightarrow \infty)=0 \\
& Z\left(\omega_{\mathrm{E}} \ll \omega \ll w_{\mathrm{B}}\right)=R_{\mathrm{B}} .
\end{aligned}
$$

The third relationship expresses mathematically the fact that for intermediate values of $\omega$, orders of magnitude from either $\omega_{\mathrm{E}}$ or $\omega_{\mathrm{B}}$, the entire system becomes purely resistive; the phase difference between the applied voltage and the resultant current is negligible. Most importantly, this value of $Z$ is equal to the bulk specimen resistance $R_{\mathrm{B}}$ that is used to calculate the specimen conductivity.

A schematic representation of $Z(\omega)$ is shown in Fig. 2 for $\omega_{\mathrm{E}} \ll \omega_{\mathrm{B}}$. The figure is an impedance plane plot, typically referred to as a Nyquist plot, and is parametrized by $\omega$, where $\omega=0$ is at the right hand side of the curve, and $\omega=\infty$ is at the left. The values of $\omega$ at the maximum values of $-Z^{\prime \prime}$ are shown. Experimentally, impedance analyzers can only produce a finite range of frequencies, and typically only the portion of the curve near $Z^{\prime}=R_{\mathrm{B}}$ is measured. For an estimate of bulk conductivity, this is all that is required. However, only under ideal conditions does the imaginary component of $Z$ go to zero at $Z^{\prime}=R_{\mathrm{B}}$. In practice, the response of a specimen is more like that shown in Fig. 3, where the bulk resistance $R_{\mathrm{B}}$ must be estimated from the value of $Z^{\prime}$ at the minimum of $-Z^{\prime \prime}$. The data collected for Fig. 3 consist of 10 data points per decade of frequency. The datum at each decade is shown as a filled circle along the curve. Therefore, the value of $R_{\mathrm{B}}$ in Fig. 3 was

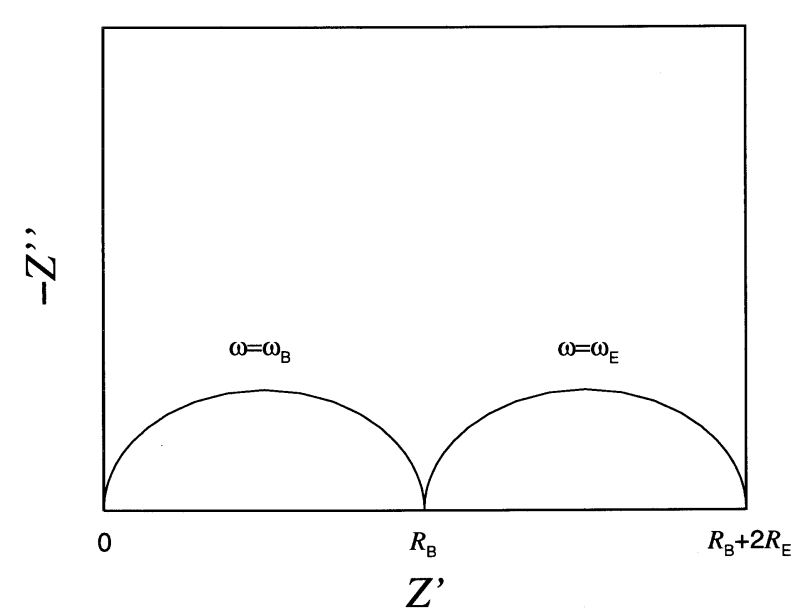

Fig. 2. Impedance plane plot showing the real $Z^{\prime}$ and imaginary $Z^{\prime \prime}$ components of the total impedance of the circuit in Fig. 1; the independent parameter is the angular frequence $\omega$. At the maxima, $\omega$ is equal to the characteristic frequency of the bulk $\omega_{\mathrm{B}}=\left(R_{\mathrm{B}} C_{\mathrm{B}}\right)^{-1}$ and the electrodes $\omega_{\mathrm{E}}=\left(R_{\mathrm{E}} C_{\mathrm{E}}\right)^{-1}$, respectively.

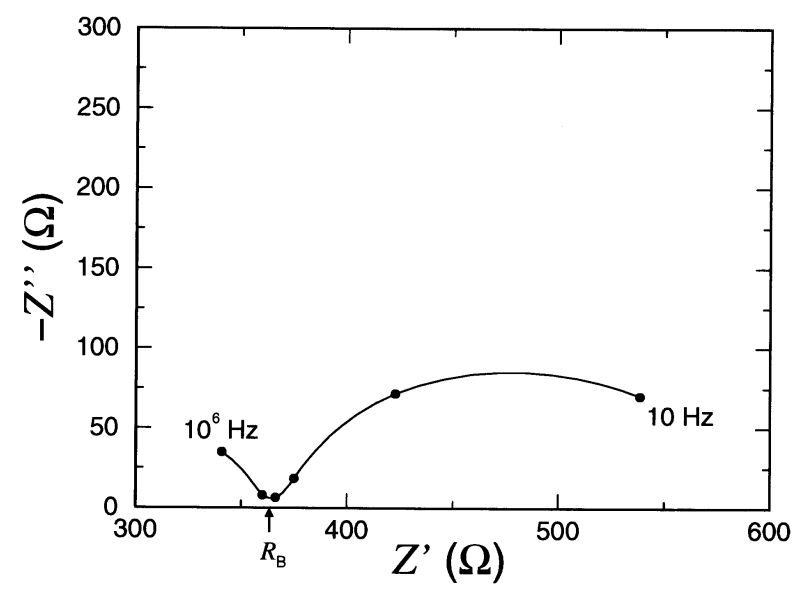

Fig. 3. Impedance plane plot showing the real $Z^{\prime}$ and imaginary $Z^{\prime \prime}$ components of the total impedance for a typical specimen in the rapid chloride test (RCT) cell; the independent parameter is the angular frequence $\omega$. The minimum of the curve is used to determine the sample bulk resistance $R_{\mathrm{B}}$. Solid circles represent data at decade frequencies; the sampled frequencies ranged from $10^{1}$ to $10^{6} \mathrm{~Hz}$.

determined at a frequency between $10 \mathrm{kHz}$ and 100 $\mathrm{kHz}$.

Although a more complete equivalent circuit for the bulk and electrode response of the RCT cell would be more complicated than that shown in Fig. $1[27,28]$, this simple circuit captures the major behavior. However, there is an additional component of the bulk impedance that is not represented in Fig. 1. A schematic cross section of the RCT with sample and holders is shown in Fig. 4. Typically, between the specimen and each brass electrode, there is a $1 \mathrm{~mm}$ to $5 \mathrm{~mm}$ gap that is filled with aqueous electrolyte: either $3 \%$ mass fraction of $\mathrm{NaCl}$ or 


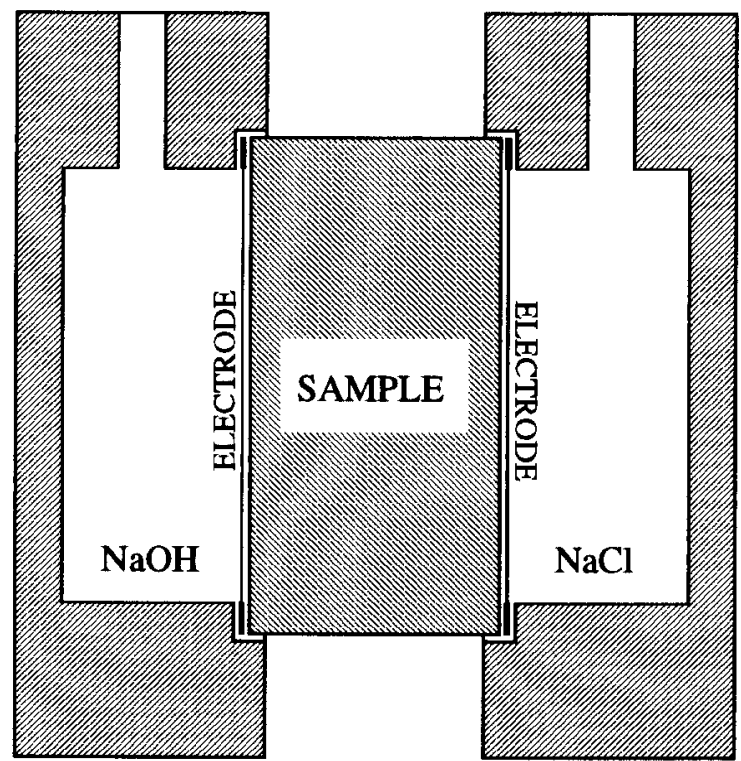

Fig. 4. A schematic cross section of the rapid chloride test cell showing the relative positions of the sample and the electrodes. The cylindrical specimen has a diameter of $100 \mathrm{~mm}$ and is $50 \mathrm{~mm}$ long from electrode to electrode. The solution volume at each end of the cell is approximately $250 \mathrm{~mL}$.

$0.3 \mathrm{~mol} / \mathrm{L} \mathrm{NaOH}$. The contribution of this resistive component to the total resistance can be calculated from the solution conductivities found in published tables [29]: $\sigma_{\mathrm{NaCl}}=4.4 \mathrm{mS} / \mathrm{mm}$ and $\sigma_{\mathrm{NaOH}}=5.7 \mathrm{mS} / \mathrm{mm}$. For the geometry of the RCT cell, the resistances divided by length are $0.029 \Omega / \mathrm{mm}$ and $0.022 \Omega / \mathrm{mm}$ for the $\mathrm{NaCl}$ and the $\mathrm{NaOH}$ solutions, respectively. Therefore, a gap of $10 \mathrm{~mm}$ between each electrode and the specimen contributes less than $1 \Omega$ to the bulk resistance. Since the bulk resistance for concrete is typically in the range of $100 \Omega$ to $1000 \Omega$, the contribution by the electrolyte between the electrodes and the sample can be neglected.

\section{Experiment \\ 3.1 Samples}

The mixture proportions of the samples prepared for this experiment were designed to yield a moderate range of transport properties and are based upon mixture proportions from previous experiments [30]. The wide range of transport properties were achieved through variations in water-cement mass ratio $m_{\mathrm{w}} / m_{\mathrm{c}}$ (commonly denoted by w/c), cement replacement by pozzolanic mineral admixtures, aggregate gradation and volume fraction, and dosage of high range water reducing admixture (HRWRA). The cement was ASTM Type I; the chemical composition is given in Table 1. The pozzolanic mineral admixture was silica fume in slurry
Table 1. Chemical composition of the Type I cement used in this experiment. The mass fractions not shown are attributable to trace elements

\begin{tabular}{lc}
\hline \hline \multicolumn{1}{c}{ Oxide } & Mass fraction $(\%)$ \\
\hline Calcium & 63.73 \\
Silica & 21.63 \\
Aluminum & 4.27 \\
Iron & 3.02 \\
Sulfur & 2.69 \\
Magnesium & 2.26 \\
Free Lime & 0.75 \\
Potassium & 0.51 \\
Sodium & 0.21 \\
\hline
\end{tabular}

form. The aggregate type was natural silica and two gradations were used: silica sand conforming to the ASTM C 778 Graded Sand designation; and a "micro" concrete aggregate composed of natural silica sand. The gradation for the "micro" concrete aggregate, based upon a report by Fuller [31], is shown in Table 2. The HRWRA was an aqueous solution with a naphtalenesulfonate mass fraction of $40 \%$. The mixture proportions of the samples used in this experiment are shown in Table 3.

Table 2. Specification for "Micro" concrete aggregate proportions. Designation C 778 indicates conformity to specification ASTM C 778. The components S15 and F95 are products of the U.S. Silica Company $^{1}$ (Ottawa, IL)

\begin{tabular}{llc}
\hline \hline Designation & $\begin{array}{c}\text { Range of } \\
\text { particle size } \\
(\mu \mathrm{m})\end{array}$ & $\begin{array}{c}\text { Mass fraction } \\
(\%)\end{array}$ \\
\hline S15 & 600 to 2360 & 37 \\
C 778 (20-30) & 600 to 850 & 19 \\
C 778 (Graded Sand) & 300 to 600 & 19 \\
F95 & 200 to 300 & 25 \\
\hline
\end{tabular}

The mixtures were prepared according to the procedures in ASTM C 109. The samples were cast in 100 $\mathrm{mm}$ diameter and $200 \mathrm{~mm}$ long cylindrical molds, covered, and stored in a $100 \%$ relative humidity chamber. At $24 \mathrm{~h}$ of age, the specimens were removed from the molds and stored ( $50 \mathrm{~d}$ to $80 \mathrm{~d}$ ) in a saturated calcium hydroxide bath until they were tested. Although no temperature controls were used, the laboratory temperature could be characterized by the interval $(20 \pm 2)^{\circ} \mathrm{C}$.

\footnotetext{
${ }^{1}$ Certain commercial materials are identified in this paper to foster understanding. Such identification does not imply recommendation or endorsement by the National Institute of Standards and Technology, nor does it imply that the materials identified are necessarily the best available for the purpose.
} 
Table 3. Sample mixture proportions. Relevant quantities are the sand gradation, the sand to cement mass ratio $m_{\mathrm{s}} / m_{\mathrm{c}}$, the water to cementitious materials mass ratio $m_{\mathrm{w}} /\left(m_{\mathrm{s}}+m_{\mathrm{c}}\right)$, the fraction of $m_{\mathrm{c}}$ replaced by silicon, high range water reducing admixture (HRWRA) dosage with respect to cement mass, and the air volume percentage as measured using a procedure based upon the specification ASTM C 185.

\begin{tabular}{|c|c|c|c|c|c|c|}
\hline Sample & Sand gradation & $m_{\mathrm{s}} / m_{\mathrm{c}}$ & $m_{\mathrm{w}} /\left(m_{\mathrm{s}}+m_{\mathrm{c}}\right)$ & $\begin{array}{c}\text { Silica } \\
(\%)\end{array}$ & $\begin{array}{c}\text { HRWR } \\
(\%)\end{array}$ & $\begin{array}{l}\text { Air } \\
(\%)\end{array}$ \\
\hline A & & & 0.30 & & & 53.7 \\
\hline B & & & 0.45 & & & 11.3 \\
\hline $\mathrm{C}$ & C 778 & 2.75 & 0.60 & & & 4.2 \\
\hline $\mathrm{D}$ & C 778 & 2.02 & 0.36 & & 0.09 & 6.7 \\
\hline $\mathrm{E}$ & Micro & 1.41 & 0.29 & & 0.40 & 1.2 \\
\hline $\mathrm{F}$ & Micro & 2.02 & 0.36 & & 0.09 & 2.0 \\
\hline G & C 778 & 2.75 & 0.49 & 10 & 0.40 & 8.5 \\
\hline $\mathrm{H}$ & Micro & 2.02 & 0.36 & 10 & 0.40 & 2.1 \\
\hline I & & & 0.25 & & & 2.6 \\
\hline $\mathrm{J}$ & C 778 & 2.75 & 0.49 & & & 8.6 \\
\hline $\mathrm{K}$ & C 778 & 1.40 & 0.29 & & 0.40 & 4.2 \\
\hline $\mathrm{L}$ & Micro & 2.75 & 0.49 & & & 3.9 \\
\hline M & Micro & 2.02 & 0.49 & & 0.09 & 0.1 \\
\hline
\end{tabular}

Note: Designation C 778 refers to a product conforming to the specification for Graded Sand in specification ASTM C 778.

Each specimen was prepared for testing according to the specifications of ASTM C 1202. A single cylinder mold was cast from each mixture and two specimens, one specimen $50 \mathrm{~mm}$ long (ASTM C 1202) and the other $100 \mathrm{~mm}$ long, taken from the middle $150 \mathrm{~mm}$ of the cylinder, were tested. The purpose of using two specimen lengths was to verify the validity of the conductivity measurement techniques. Conductivity, an intrinsic property, is independent of specimen geometry and size. A reliable technique for determining specimen conductivity should obtain equivalent results from replicate specimens with different lengths.

\subsection{IS and Initial Current Measurements}

The specimens were mounted into the RCT cells and the $\mathrm{NaOH}(0.3 \mathrm{~mol} / \mathrm{L})$ and $\mathrm{NaCl}(3 \%)$ chambers were filled. A commercial impedance analyzer was then connected to the RCT cell banana jacks. Using a voltage of approximately $1 \mathrm{~V}$ (peak-to-peak), with a zero volt $\mathrm{dc}$ offset bias, across the RCT cell, the analyzer scanned frequencies from $10 \mathrm{~Hz}$ to $1 \mathrm{MHz}$, completing the test in approximately $1 \mathrm{~min}$; results using ac potentials ranging from $0.1 \mathrm{~V}$ to $1.0 \mathrm{~V}$ yielded similar results. The data were stored in the computer for analysis to determine the value of $R_{\mathrm{B}}$.

At the completion of the IS measurement, the analyzer leads were removed from the cell and the cell was connected to a commercial dc power supply capable of two-way communication to a computer via an IEEE-488 interface. The computer program would initiate the test, query the power supply for the initial current, and subsequently query the power supply for the current every $60 \mathrm{~s}$ until the completion of the test. The power supply was equipped with remote sensing to compensate for the voltage drop along the power cable. This ensured that the voltage delivered to the RCT cell was always within $0.1 \mathrm{~V}$ of $60 \mathrm{~V}$.

\section{Calculated Quantities}

The reported values are calculated quantities based upon the physical measurements. For clarity, these calculated quantities shall be defined explicitly. The total charge passed $Q_{\mathrm{T}}$ is calculated from the measurements of the currents $I_{i}$ that were carried out at times $t_{i}$. Each $t_{i}$ occurred at the $i$ th minute of the test:

$$
Q_{\mathrm{T}}=\frac{1}{2} \sum_{i=1}^{360}\left(I_{i}+I_{i-1}\right)\left(t_{i}-t_{i-1}\right)
$$

This method conforms to the procedure specified in ASTM C 1202. The initial RCT resistance $R_{0}$ was calculated from the initial current $I_{0}$ :

$$
R_{0}=\frac{60 \mathrm{~V}}{I_{0}}
$$

As indicated in Fig. 3, the bulk resistance $R_{\mathrm{B}}$ measured using IS was determined from the value of $Z^{\prime}$ at the minimum value of $-Z^{\prime \prime}$. Specimen conductivities $\sigma_{\text {IS }}$ and $\sigma_{\mathrm{RCT}}$ were calculated using the measured resistance and the specimen length $L$ and area $A$ :

$$
\sigma_{\mathrm{IS}}=\frac{L}{A R_{\mathrm{B}}} \quad \sigma_{\mathrm{RCT}}=\frac{L}{A R_{0}} .
$$


Since a number of studies reported in the literature have used a fixed frequency, it will be instructive to determine the validity of this approach. The quantity $R_{20}$ is the real component of $Z(\omega)$ at a frequency of $20 \mathrm{kHz}$, a frequency that has been used in similar experiments with a fixed frequency $[16,18,19]$.

\section{Results}

The results of the experiment are summarized in Table 4 and are in qualitative agreement with values cited elsewhere $[3,17,22,23]$. The specimens are grouped by sample for direct comparison between specimens with different lengths from the same mixture. Although most of the specimens were more than two months of age at the time of testing, results of the total charge passed $Q_{\mathrm{T}}$ indicate that specimens from a range of qualities were tested. In fact, some of the tests had to be terminated due to excessive heating. Unfortunately, there were also some specimens that have no IS data due to computer software problems. However, the comparison among $R_{\mathrm{B}}, R_{20}$, and $R_{0}$ can be carried out for all but five specimens.

The issue of measurement uncertainty is addressed in Appendix A. Expanded uncertainties $U$ reported in Table 4 represent an estimate of two standard deviations, or an estimated coverage of approximately $95 \%$. The uncertainties in the total charge passed $Q_{\mathrm{T}}$ were all less than $2 \mathrm{C}$ at this level, with most of the uncertainties less than 1 C. Appendix A addresses the calculations of the reported uncertainties, and concentrates on the complicated issue of the uncertainty in $Q_{\mathrm{T}}$.

\subsection{Conductivity}

For all but three specimens, the values $\sigma_{\mathrm{RCT}}$ and $\sigma_{\mathrm{IS}}$ for an individual specimen differed by less than $5 \%$. This fact is demonstrated graphically in Fig. 5. Immediately apparent from graph is range over which the agree-

Table 4. Comparison of results between $60 \mathrm{~V}$ rapid chloride test (RCT) measurements and impedance spectroscopy (IS) measurements. ${ }^{a}$

\begin{tabular}{|c|c|c|c|c|c|c|c|c|c|}
\hline Specimen & $\begin{array}{c}\text { Length } \\
(\mathrm{mm})\end{array}$ & $\begin{array}{l}\text { Age } \\
\text { (d) }\end{array}$ & $\begin{array}{l}Q_{\mathrm{T}} \\
(\mathrm{C})\end{array}$ & $\begin{array}{r}I_{0} \\
\text { (A) }\end{array}$ & $\begin{array}{l}R_{0} \\
(\Omega)\end{array}$ & $\begin{array}{l}R_{\mathrm{B}} \\
(\Omega)\end{array}$ & $\begin{array}{l}R_{20} \\
(\Omega)\end{array}$ & $\begin{array}{c}\sigma_{\mathrm{RCT}} \\
(\mu \mathrm{S} / \mathrm{mm})\end{array}$ & $\begin{array}{c}\sigma_{\mathrm{IS}} \\
(\mu \mathrm{S} / \mathrm{mm})\end{array}$ \\
\hline A-1 & 50 & 66 & $\mathrm{~b}$ & 0.5995 & $100.1 \pm 0.1$ & 98 & 98 & $63.6 \pm 4.0$ & $65.0 \pm 4.3$ \\
\hline A-2 & 100 & 66 & $10865 \pm 2$ & 0.2755 & $217.8 \pm 0.5$ & 215 & 213 & $58.5 \pm 3.7$ & $59.2 \pm 3.8$ \\
\hline B-1 & 50 & 73 & b & 0.9435 & $63.6 \pm 0.1$ & $\mathrm{c}$ & & $100.1 \pm 6.3$ & \\
\hline B-2 & 100 & 71 & b & 0.6238 & $96.2 \pm 0.1$ & $\mathrm{c}$ & & $132.4 \pm 8.4$ & \\
\hline $\mathrm{C}-1$ & 50 & 64 & b & 0.3622 & $165.7 \pm 0.3$ & $\mathrm{c}$ & & $38.4 \pm 2.4$ & \\
\hline $\mathrm{C}-2$ & 100 & 64 & $4389 \pm 1$ & 0.1592 & $377.0 \pm 1.5$ & 364 & 364 & $33.8 \pm 2.1$ & $35.0 \pm 2.2$ \\
\hline D-1 & 50 & 55 & $\mathrm{~b}$ & 0.2935 & $204.5 \pm 0.5$ & 203 & 202 & $31.1-2.0$ & $31.4 \pm 2.0$ \\
\hline $\mathrm{D}-2$ & 100 & 56 & $2818 \pm 1$ & 0.1103 & $544.1 \pm 3.0$ & 543 & 540 & $23.4 \pm 1.5$ & $23.4 \pm 1.5$ \\
\hline E-1 & 50 & 69 & $4564 \pm 1$ & 0.1358 & $441.8 \pm 2.0$ & 444 & 440 & $14.4 \pm 0.9$ & $14.3 \pm 0.9$ \\
\hline E-2 & 100 & 69 & $1455 \pm 1$ & 0.0580 & $1035 \pm 11$ & 1030 & 1014 & $12.3 \pm 0.8$ & $12.4 \pm 0.8$ \\
\hline $\mathrm{F}-1$ & 50 & 48 & $6905 \pm 1$ & 0.1835 & $327.1 \pm 1.1$ & 336 & & $19.5 \pm 1.2$ & $18.9 \pm 1.2$ \\
\hline $\mathrm{F}-2$ & 100 & 49 & $2418 \pm 1$ & 0.0935 & $641.8 \pm 4.2$ & 638 & 631 & $19.8 \pm 1.3$ & $20.0 \pm 1.3$ \\
\hline G-1 & 50 & 76 & $4603 \pm 1$ & 0.1520 & $394.7 \pm 1.6$ & 379 & 373 & $16.1 \pm 1.0$ & $16.8 \pm 1.1$ \\
\hline $\mathrm{G}-2$ & 100 & 76 & $1964 \pm 1$ & 0.0781 & $768.7 \pm 5.9$ & 759 & 738 & $16.6 \pm 1.1$ & $16.8 \pm 1.1$ \\
\hline $\mathrm{H}-1$ & 50 & 75 & $1591 \pm 1$ & 0.0588 & $1020 \pm 11$ & 974 & 963 & $6.2 \pm 0.4$ & $6.5 \pm 0.4$ \\
\hline $\mathrm{H}-2$ & 100 & 75 & $679 \pm 1$ & 0.0289 & $2074 \pm 43$ & 2050 & 1992 & $6.1 \pm 0.4$ & $6.2 \pm 0.4$ \\
\hline I-1 & 50 & 69 & $\mathrm{~b}$ & 0.1980 & $303.1 \pm 1.0$ & c & & $21.0 \pm 1.3$ & \\
\hline $\mathrm{I}-2$ & 100 & 69 & $3363 \pm 1$ & 0.1021 & $587.9 \pm 3.5$ & $\mathrm{c}$ & & $21.7 \pm 1.4$ & \\
\hline $\mathrm{J}-1$ & 50 & 77 & $9128 \pm 2$ & 0.2514 & $238.6 \pm 0.6$ & 234 & 228 & $26.7 \pm 1.7$ & $27.2 \pm 1.7$ \\
\hline $\mathrm{J}-2$ & 100 & 77 & $3625 \pm 1$ & 0.1384 & $433.5 \pm 1.9$ & 432 & 415 & $29.4 \pm 1.9$ & $29.5 \pm 1.9$ \\
\hline $\mathrm{K}-1$ & 50 & 75 & $6944 \pm 1$ & 0.1848 & $324.6 \pm 1.1$ & 362 & 307 & $19.6 \pm 1.2$ & $17.6 \pm 1.1$ \\
\hline $\mathrm{K}-2$ & 100 & 75 & $2271 \pm 1$ & 0.0807 & $743.6 \pm 5.6$ & 704 & 704 & $17.1 \pm 1.1$ & $18.1 \pm 1.1$ \\
\hline L-1 & 50 & 78 & $7662 \pm 1$ & 0.2376 & $252.5 \pm 0.7$ & 260 & 235 & $25.2 \pm 1.6$ & $24.5 \pm 1.6$ \\
\hline L-2 & 100 & 78 & $4021 \pm 1$ & 0.1492 & $402.1 \pm 1.7$ & 412 & 376 & $31.7 \pm 2.0$ & $30.9 \pm 2.0$ \\
\hline M-1 & 50 & 76 & $11067 \pm 2$ & 0.2921 & $205.4 \pm 0.5$ & 222 & 193 & $31.0 \pm 2.0$ & $28.7 \pm 1.8$ \\
\hline M-2 & 100 & 76 & $5373 \pm 1$ & 0.1804 & $332.6 \pm 1.1$ & 341 & 309 & $38.3 \pm 2.4$ & $37.3 \pm 2.4$ \\
\hline
\end{tabular}

\footnotetext{
${ }^{\text {a }}$ The RCT resistance $R_{0}$ was calculated from the initial RCT current $I_{0}$ and the bulk resistance $R_{\mathrm{B}}$ was determined from impedance spectroscopy. The RCT conductivity $\sigma_{\mathrm{RCT}}$ was calculated from the RCT resistance $R_{0}$ and the IS conductivity $\sigma_{\mathrm{IS}}$ was calculated from the IS bulk resistance $R_{\mathrm{IS}}$. The total charge $Q_{\mathrm{T}}$ passed during the $6 \mathrm{~h}$ RCT is the value reported from the standardized test method. The real component of the impedance at $20 \mathrm{kHz} R_{20}$ is also shown for comparison purposes. Assigned uncertainties are expanded uncertainties (coverage factor $k=2$ and hence two deviation estimates); details of the uncertainty evaluation are given in Appendix A.

${ }^{\mathrm{b}}$ Test terminated due to excessive heating.

${ }^{\mathrm{c}}$ No measurement.
} 


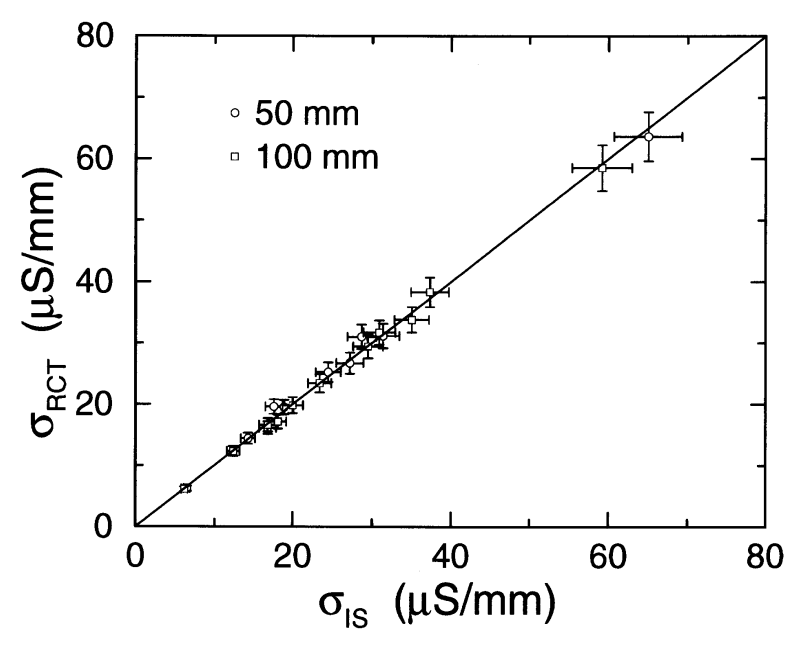

Fig. 5. A comparison between the sample conductivity $\sigma$ estimated from impedance spectroscopy (IS) and conductivity estimated from the rapid chloride test (RCT) initial current for both the $50 \mathrm{~mm}$ and the $100 \mathrm{~mm}$ long specimens. The error bars are two standard deviation estimates and the line delineates a 1:1 relationship.

ment is valid. The data shown on the graph represent samples that passed total charges ranging from $679 \mathrm{C}$ to $10865 \mathrm{C}$. In addition, there are data shown that represent specimens that did not finish the $6 \mathrm{~h}$ test due to excessive heating.

Since IS gives the most accurate estimate of conductivity, and since the conductivities of replicate specimens of different lengths are not equal, the difference in $\sigma_{\text {IS }}$ between these specimens of different lengths must be due to specimen-specimen variability. Since the values of $\sigma_{\mathrm{RCT}}$ and $\sigma_{\mathrm{IS}}$ for each specimen are nearly equal, the initial current measurements yield a direct and accurate measure of specimen conductivity. Therefore, the ratio of $I_{0}$ values for the two specimens is directly proportional to the ratio of specimen conductances (inverse of resistance) However, the ratio of $Q_{\mathrm{T}}$ values does not equal the ratio of $I_{0}$ values. Therefore, $Q_{\mathrm{T}}$ is not a direct measure of specimen conductivity.

With few exceptions, the resistance measurements at $20 \mathrm{kHz} R_{20}$ are within a few percent of $R_{\mathrm{B}}$. This suggests that there may exist a constant intermediate frequency one could use with the RCT cell to determine sample conductivity to within an acceptable level of uncertainty. However, a suitable frequency should be chosen with care. Using a frequency of $100 \mathrm{~Hz}$, as was used elsewhere [22], would not be advisable due to the substantial contribution by the imaginary portion of the impedance. A fixed frequency test would reduce the cost of an ac test that incorporated the RCT cell. However, with few exceptions, the initial dc resistances are a more accurate estimate than the $20 \mathrm{kHz}$ resistances $R_{20}$ measured here.

\subsection{Total Charge}

Although the total charge passed $Q_{\mathrm{T}}$ increased as the specimen conductance increased, the values are not linearly proportional to one another. Samples for which there are values of $Q_{\mathrm{T}}$ for both specimen lengths, the values are not inversely proportional to the specimen length; the value of $Q_{\mathrm{T}}$ for the $50 \mathrm{~mm}$ specimen was always significantly greater than twice the value for the $100 \mathrm{~mm}$ specimen. Figure 6 shows the measured current for the two specimens from Sample F. The current through the $100 \mathrm{~mm}$ specimen is nearly constant throughout the test. The current through the $50 \mathrm{~mm}$ specimen appears to increase linearly after approximately $100 \mathrm{~min}$. Although the initial currents differed by a factor of two, the final currents did not. The difference is due to ohmic heating.

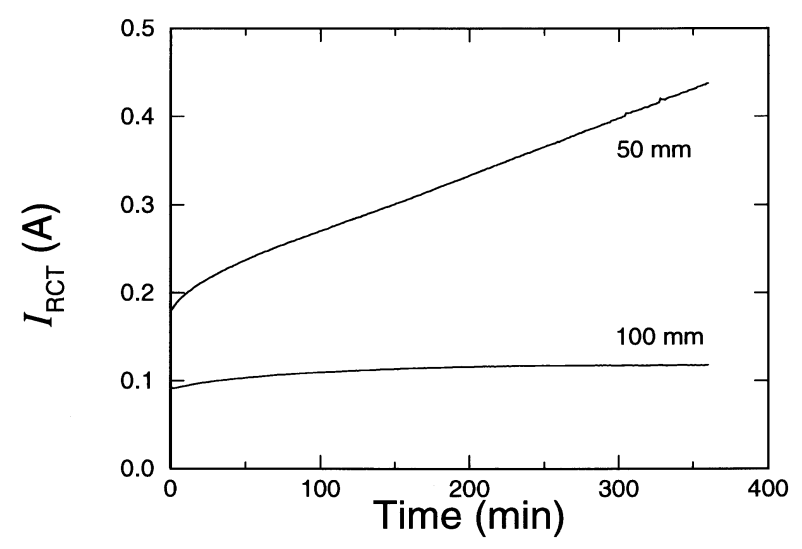

Fig. 6. Rapid chloride test current $I_{\mathrm{RCT}}$ as a function of time for the $50 \mathrm{~mm}$ and the $100 \mathrm{~mm}$ specimens taken from Sample F.

Since fluid conductivity increases by approximately $2 \%$ per degree Celsius [10,11], and assuming that specimen pore fluid conductivity behaves in a similar manner, one could estimate sample temperature from the relative change in current. Unfortunately, the specimen temperatures were not measured at the time of the tests and a duplicate experiment that included temperature measurements could not be conducted because the specimens had been discarded.

To demonstrate the effect of temperature, an additional test was performed on a completely different sample from the Federal Highway Administration. For this specimen, the temperature was monitored using an immersion temperature probe incorporating a precision thermistor. The probe was demonstrated to be accurate to within $1{ }^{\circ} \mathrm{C}$. The temperature of the solutions at each end of the specimen was measured periodically throughout the RCT test. The data are shown as filled symbols in Fig. 7. Along with the symbols is a curve 


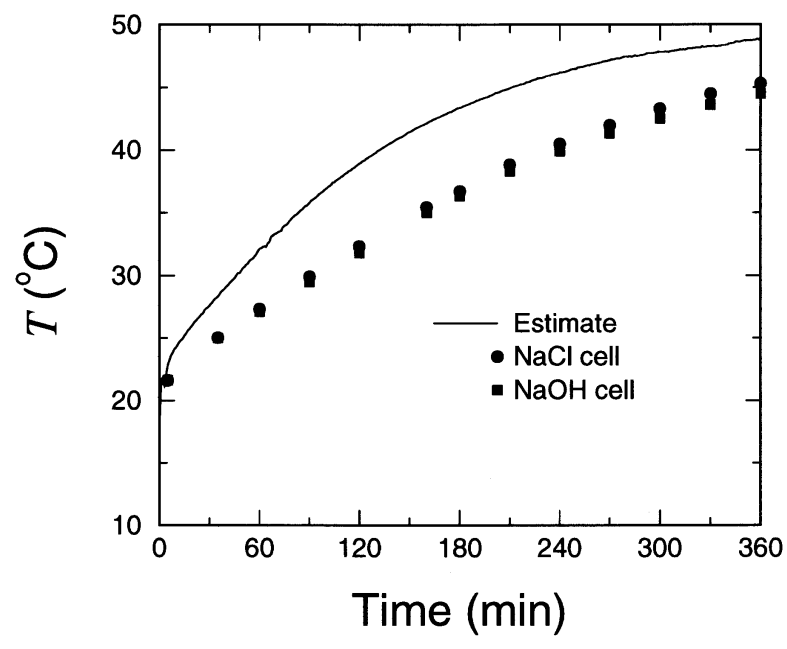

Fig. 7. Calculated specimen temperature $T$ (solid line) estimated from changes in the rapid chloride test cell current. Measured temperature values (filled circles and squares) were sampled from the solution at each end of the cell.

that shows the estimated specimen temperature based upon the increase in current passing through the specimen. Although the measured and estimated values are not equal, they agree to within $10{ }^{\circ} \mathrm{C}$ throughout the test. This is reasonable since the heat generated within the specimen is lost to the solutions and to the room. Also, the results are in general agreement with laboratory experience and with results reported elsewhere [20,21].

\subsection{Current at Early Times}

It is interesting to note the early conductivity response of the sample to the application of the $60 \mathrm{~V}$ required by the standardized RCT. Figure 8 is a plot of effective specimen conductivity calculated from the RCT current for the two specimens from Sample F during the first 4 min of the RCT. The solid lines shown are only meant to guide the reader's eyes. The dashed lines delineate the sample conductivities using IS. The figure shows the effects of two phenomena: a decrease in current due to the accumulation of polarization charge, and an increase in current due to ohmic heating.

Using these data from Specimen F, it is difficult to distinguish the proper time at which to measure the RCT current to ensure an accurate estimate of $\sigma_{\text {IS. }}$. One could argue that the proper value should be determined from an extrapolation to zero time using the values measured at $1 \mathrm{~min}$ and later. Although this method would be relatively accurate for the $50 \mathrm{~mm}$ specimen, it would not be justifiable for the $100 \mathrm{~mm}$ specimen. The estimate using the value at $t=0$ seems to be a reasonable compromise. Since the values in the figure only vary by

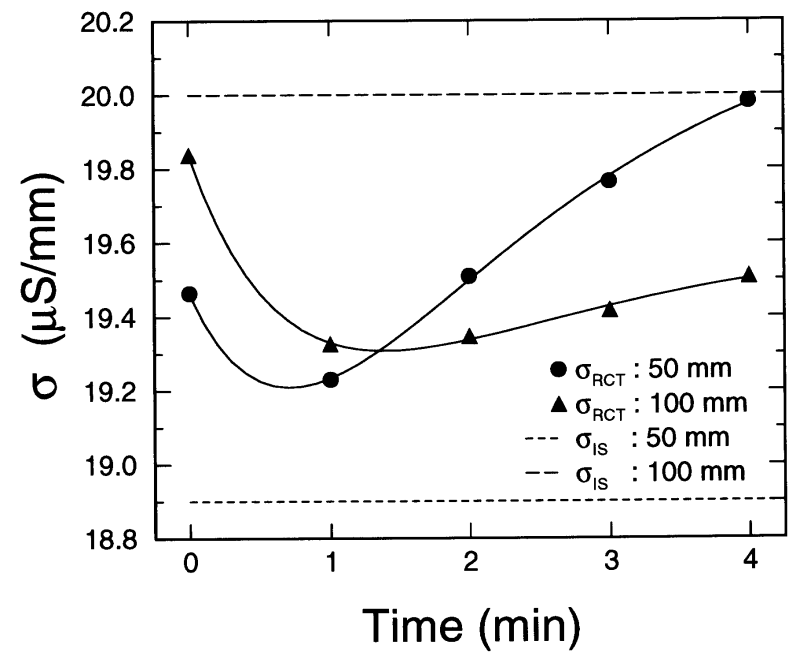

Fig. 8. Rapid chloride test (RCT) cell conductivity during the first four minutes of the standard test. The filled symbols were calculated from the measured RCT cell current for both the $50 \mathrm{~mm}$ and the $100 \mathrm{~mm}$ specimen from Sample F; the solid lines are only meant to guide the eye. The dashed lines are the corresponding RCT cell conductivities as measured using impedance spectroscopy (IS).

approximately $4 \%$ during the first $4 \mathrm{~min}$ of the test, it would seem as though sufficiently accurate estimates of sample conductivity could be made using the dc current measurements at any time during the first few minutes.

\section{Discussion \\ 6.1 Previous $I_{0}$ vs $\sigma$ Data}

The direct relationship between the initial RCT current $I_{0}$ and sample conductivity established in this experiment is in contrast to results reported elsewhere. Hansen et al. [32] reported both the initial current and the ac impedance at $1 \mathrm{kHz}$. However, their data showed that, for a given specimen, the ac impedance was considerably greater than the resistance calculated from the initial current. This may be explained using the IS data for the RCT cell that is shown in Fig. 3. The real component of the total impedance at $1 \mathrm{kHz}$ is greater than $R_{\mathrm{B}}$. Also, if the output of the apparatus used in the experiment by Hansen et al. is the magnitude of the impedance $|Z|=\left(Z^{\prime 2}+Z^{\prime \prime 2}\right)^{1 / 2}$, the difference is accentuated by the greater contribution of $Z^{\prime \prime}$ at $1 \mathrm{kHz}$ than of $Z^{\prime}=R_{\mathrm{B}}$. However, the general relationship between initial current and charge passed given in Table 7 of Hansen et al. agree with the results reported here.

The experiments reported by Feldman and coworkers $[20,21]$ also included measurements of specimen impedance and RCT initial current. The impedance measurements were conducted at $10 \mathrm{kHz}$. However, cal- 
culations of specimen resistivity using their RCT initial current differ from the IS measurements by $20 \%$ or more in most cases. The source of the discrepancy cannot be explained by our results since the real component of $Z$ at $20 \mathrm{kHz}$ reported in Table 4 is typically within a few percent of $R_{\mathrm{B}}$.

\subsection{Significance for Diffusivity}

The significance of a rapid test for determining sample conductivity is the relationship between bulk conductivity and bulk diffusivity. The Nernst-Einstein [9] equation can be used to relate the bulk diffusion coefficient $D_{\mathrm{i}}$ for ion species i to the bulk conductivity $\sigma_{\mathrm{B}}$ :

$$
\frac{D_{\mathrm{i}}}{D_{\mathrm{i}}^{\mathrm{f}}}=\frac{\sigma_{\mathrm{B}}}{\sigma_{\mathrm{P}}} .
$$

The quantity $D_{\mathrm{i}}^{\mathrm{f}}$ is the diffusivity of ion species $i$ in bulk water, and the quantity $\sigma_{\mathrm{P}}$ is the sample pore fluid conductivity. Since the values of $D_{\mathrm{i}}^{\mathrm{f}}$ can be obtained from tables [10], $D_{\mathrm{i}}$ could be calculated explicitly from bulk conductivity measurements if the value of $\sigma_{\mathrm{P}}$ could be determined using a technique such as the expression of pore fluid $[28,33]$.

For the existing RCT apparatus to be useful to researchers and practitioners, it must be able to measure scientifically useful quantities such as diffusivity or it must be able to report empirical measurements that are directly related to physical processes. It has been shown here that the total electrical charge passed during the RCT $6 \mathrm{~h}$ conduction test is not directly proportional to the true dc resistance, and so is not directly related to diffusivity, which is the process of interest. However, the initial current may be used to accurately estimate $\sigma_{\mathrm{B}}$.

A second calculation shows that the RCT test does not simulate chloride transport through the sample, and so does not simulate real-world conditions. The magnitude of the drift velocity $v_{\mathrm{D}}$ of the chloride ions through the RCT cell is calculated from a modification of the Einstein equation [9]:

$$
v_{\mathrm{D}}=\frac{z e E D}{k T}
$$

The relevant quantities are the ion valence $z$, the elementary charge $e$, the magnitude of the applied electric field $E$, the bulk diffusivity $D$, the Boltzmann constant $k$, and the absolute temperature $T$. This equation for the drift velocity $v_{\mathrm{D}}$ can be used to determine the time required for chloride ions to traverse a specimen, and is in agreement with the experimental results of both McGrath and Hooton [34] and Sugiyama et al. [35].
The drift velocity equation can be simplified using the geometry of the RCT cell $\left(E=1.2 \mathrm{~V} \mathrm{~mm}^{-1}\right)$ and assuming a constant temperature of $300 \mathrm{~K}$ :

$$
v_{\mathrm{D}}=D \times 46.4 \mathrm{~mm}^{-1}
$$

This equation can be simplified further by expressing the diffusivity as a ratio of the chloride ion bulk diffusivity at $25^{\circ} \mathrm{C}\left(2.0 \times 10^{-3} \mathrm{~mm}^{2} \mathrm{~s}^{-1}[10]\right)$ to the formation factor $F$ [36,37]. The chloride ion penetration depth $\delta$ during the standard $6 \mathrm{~h} \mathrm{RCT}$, as a function of the formation factor $F$, is simply the drift velocity $v_{\mathrm{D}}$ times 21600 seconds:

$$
\delta=\frac{200}{F} \mathrm{~cm}
$$

Since typical values of the formation factor $F$ for $28 \mathrm{~d}$ specimens range from 100 to 1000 [38,39], the chloride ions do not traverse the specimen during the rapid chloride test. Therefore, the standard $6 \mathrm{~h}$ RCT does not simulate chloride transport through the specimen because the chloride ions typically penetrate only a fraction of the specimen thickness during the test.

\subsection{Conductivity vs Total Charge Correlations}

Since there have been previous attempts to correlate specimen conductivity to the total charge passed, it will be useful to study this behavior using the data from this experiment. Figure 9 contains a plot of the measured conductivities $\sigma_{\mathrm{IS}}$ as a function of the total charge

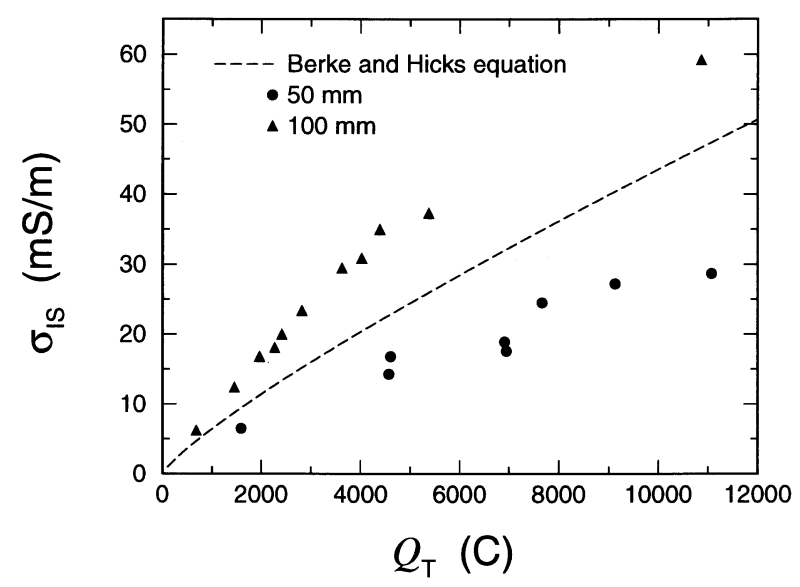

Fig. 9. Sample conductivity $\sigma_{\mathrm{IS}}$ as measured using impedance spectroscopy (IS) versus the total charge passed $Q_{\mathrm{T}}$ during the $6 \mathrm{~h}$ rapid chloride test (RCT). The filled symbols denote measured data for both $50 \mathrm{~mm}$ and $100 \mathrm{~mm}$ specimens. The dashed curve is the regression equation of Berke and Hicks [19] for estimating sample conductivity based upon total charge passed during the $6 \mathrm{~h}$ test. 
passed $Q_{\mathrm{T}}$ for the data in this experiment. When considering all the data for a given specimen length, the relationship is not linear over the entire range of $Q_{\mathrm{T}}$ values. The experiment of Zhao et al. [40] correlated total charge to specimen resistance, but only for specimens passing less than $4500 \mathrm{C}$. Based upon the data shown in Fig. 9, one would expect a reasonable correlation between total charge passed and specimen conductivity for specimens passing fewer than $4500 \mathrm{C}$. However, extrapolating a linear correlation for fewer than $4500 \mathrm{C}$ to specimens passing as much as $10000 \mathrm{C}$ could prove to be erroneous.

The dashed curve in Fig. 9 represents the empirical prediction of Berke and Hicks (BH) [19] that was developed from correlations between measurements of total charge and conductivity measurements using a lollipop apparatus shown schematically in Fig. 10. The apparatus consists of a $9.5 \mathrm{~mm}$ diameter reinforcing bar embedded along the axis of a $76 \mathrm{~mm}$ diameter, $152 \mathrm{~mm}$ long concrete cylinder, with the reinforcing bar positioned $38 \mathrm{~mm}$ from the far end of the cylinder. The top

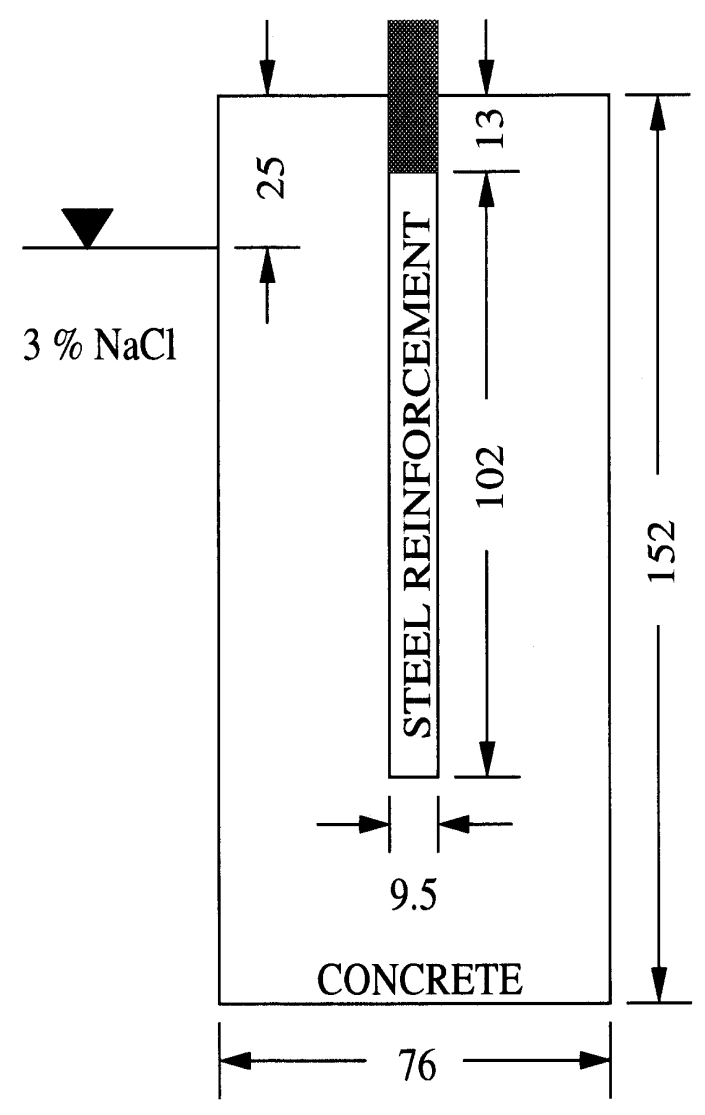

Fig. 10. Schematic cross section of lollipop apparatus used elsewhere $[16,18,19]$ to measure specimen conductivity. Dimensions shown are in millimeters. The sample is placed into a $3 \%$ mass fraction solution of sodium chloride that contains an additional electrode.
$25 \mathrm{~mm}$ of the rod penetrating the cylinder is coated with epoxy. Since the BH equation was developed using $50 \mathrm{~mm}$ specimens, it should not be expected to predict the response of $100 \mathrm{~mm}$ specimens. Also, the equation was developed using data with few values of $Q_{\mathrm{T}}$ greater than 4000 C. For our experiment, the BH equation is a reasonably good predictor of the $50 \mathrm{~mm}$ data for $Q_{\mathrm{T}}$ less than $4000 \mathrm{C}$, but is a poor predictor for values of $Q_{\mathrm{T}}$ greater than $4000 \mathrm{C}$. This is to be expected, given the parameter space over which the equation was developed. However, there are two features worthy of note. Use of the equation for samples passing greater than $4000 \mathrm{C}$ would introduce large errors. Also, the estimate is consistently greater than the conductivity values measured here. This artifact may be due to the longitudinal component of the current originating from the end of the reinforcement bar used in the BH experiment. This additional current would cause an overestimate of the specimen conductivity, as is demonstrated in Fig. 9.

\subsection{Corrosion Arc}

An interesting component in the Nyquist plots appeared near the completion of this experiment. Samples $\mathrm{J}$ through $\mathrm{M}$ were cast and tested approximately three months after samples A through I. The IS results from samples A through I were fairly consistent. However, samples $\mathbf{J}$ through $\mathbf{M}$ exhibited an additional feature in the Nyquist plot such as that shown in Fig. 11 from specimen K-2. The data shown in the figure were measured at the beginning of the RCT, just prior to the

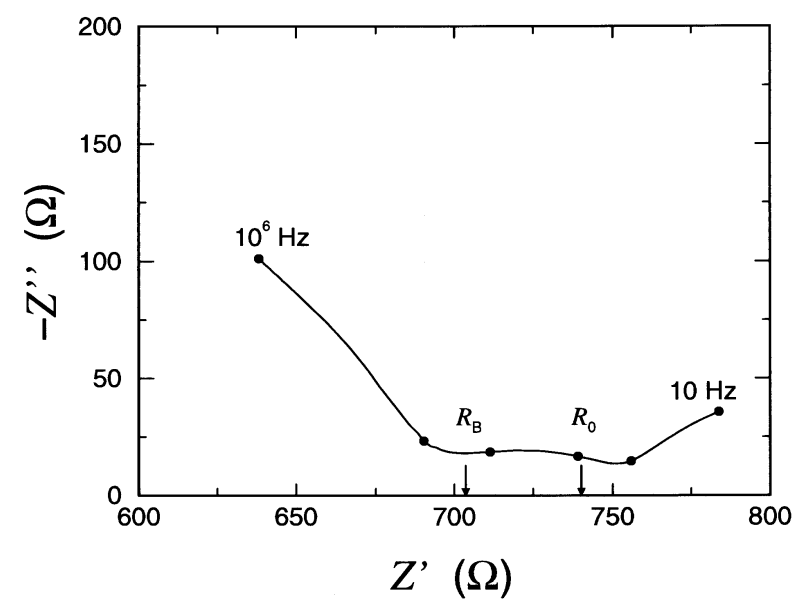

Fig. 11. Impedance plane plot showing the real $Z^{\prime}$ and imaginary $Z^{\prime \prime}$ components of the total impedance for Specimen K-2 in the rapid chloride test (RCT) cell. The independent parameter is the angular frequence $\omega$; solid circles represent data at decade frequencies. The specimen bulk resistance $R_{\mathrm{B}}$ and the sample resistance $R_{0}$, which based upon the initial direct current measurement, are shown for comparison purposes. 
application of $60 \mathrm{~V}$ dc. The bulk arc can be seen at $Z^{\prime}<700 \Omega$, and the electrode arc can be seen at $Z^{\prime}>750$ $\Omega$. The interval $700 \Omega<Z^{\prime}<750 \Omega$ has an additional arc, possibly due to corrosion accumulating over the duration of the entire experiment. However, the cell was damaged during an attempt to clean one of the brass electrodes in order to confirm the corrosion theory.

The "corrosion" arc presents a possible difficulty in using the RCT cell for determining the sample conductivity. The Nyquist plot of Specimen K-2 in Fig. 11 has two arrows delineating the values $R_{\mathrm{B}}$ and $R_{0}$. The value of $R_{\mathrm{B}}$ is an accurate estimate of the sample resistance since one would expect the actual value to be at the intercept of the bulk arc and the $Z^{\prime}$ axis; one can show this by adding another RC pair in the equivalent circuit shown in Fig. 1 to approximate corrosion and observing the result. The measured value of $R_{0}$ is affected by the presence of the intermediate arc. Despite this, the values for $\sigma_{\mathrm{IS}}$ and $\sigma_{\mathrm{RCT}}$ differ by less than $11 \%$ for specimens $\mathrm{J}$ through $\mathrm{M}$.

\section{Summary}

The results demonstrated that the total charge passed during the $6 \mathrm{~h}$ ASTM C 1202 rapid chloride test (RCT) was not an accurate indication of specimen conductivity. For every mixture proportion studied, the shorter specimen had a disproportionately greater total charge passed. This would be expected based upon the effects of ohmic heating.

A measurement of the initial current $(t=0)$ during the ASTM C 1202 rapid chloride test provides an estimate of specimen conductivity which is typically within $5 \%$ of the value determined from impedance spectroscopy using a frequency spectrum of $10 \mathrm{~Hz}$ to $1 \mathrm{MHz}$. These results were confirmed using otherwise similar specimens of different lengths. Based upon the NernstEinstein relationship between specimen conductivity and specimen diffusivity, these results imply that an instantaneous measurement of current can yield quantitative information about the diffusivity of the specimen. Further, data obtained during the start of the RCT suggest that the dc current measured at any time during the first few minutes of the test would yield similar results.

Impedance spectroscopy impedance-plane plots also revealed an electrochemical feature in tests performed later in the experiment. This feature may be attributable to corrosion of the brass electrodes. The feature was responsible for a small bias (less than a $10 \%$ difference) between bulk conductivities measured by impedance spectroscopy and the initial RCT current. Therefore, this suggests that implementing a rapid test based only on the initial current may require frequent monitoring of the electrode surface condition, or the use of electrodes made from a material that does not corrode in the testing solutions.

\section{Appendix A. Evaluation of Uncertainty 8.1 Measured Quantities}

The evaluation of uncertainty requires assumptions about the magnitudes of the uncertainties attributed to the individual measurements. Unfortunately, none of the individual measurement uncertainties are based upon a statistical analysis. Rather, they are based upon engineering judgment, classified as Type B $[41,42]$ by the International Organization for Standardization (ISO).

Table 5 summarizes the various measurement uncertainties for this experiment. Since the uncertainty in each measured quantity must be quantified, a probability distribution must be chosen for each. Here, a Gaussian distribution is used for convenience. The uncertainties are characterized by an expanded uncertainty $U=k u_{\mathrm{c}}$, where $u_{\mathrm{c}}$ is the standard uncertainty, that is, estimated standard deviation, and $k$ is the coverage factor. The expanded uncertainties $U$ in Table 5 correspond to two standard deviation estimates $(k=2)$, implying a coverage of approximately $95 \%$.

Table 5. Expanded uncertainties $U$ (coverage factor $k=2$ ) for the measured quantities voltage $V$, current $I$, current measurement time $t$, specimen length $L$, specimen diameter $D$, and bulk resistance $R_{\mathrm{B}}$.

\begin{tabular}{cll}
\hline \hline $\begin{array}{c}\text { Measured } \\
\text { quantity }\end{array}$ & \multicolumn{1}{c}{$\begin{array}{c}\text { Uncertainty } \\
\text { source }\end{array}$} & $U$ \\
\hline$V$ & Equipment specifications & $0.054 \mathrm{~V}$ \\
$I$ & Equipment specifications & $0.0006 \mathrm{~A}$ \\
$t$ & Equipment specifications & $0.120 \mathrm{~s}$ \\
$L$ & Tolerance reported in ASTM C 1202 & $3 \mathrm{~mm}$ \\
$D$ & Tolerance reported in ASTM C 470 & $0.02 \mathrm{D}$ \\
$R_{\mathrm{B}}$ & Typical nearest neighbor distance at minimum & $2.0 \Omega$ \\
& & \\
& & \\
\hline
\end{tabular}

The two standard deviation estimates are based upon engineering judgment. If a reputable electronics manufacturer specifies that a voltmeter has an "accuracy" of $0.054 \mathrm{~V}$, it is assumed here that $U=0.054 \mathrm{~V}$. This is a conservative estimate because one would generally expect a better than $95 \%$ confidence that the device is within $U=2 u_{\mathrm{c}}$. In Table 5 , the values of $U$ for the equipment specifications are the accuracies specified by the manufacturer.

Two of the remaining uncertainties in Table 5 are for dimensional measurements. Unfortunately, statistical measurements of the corresponding dimensions of each specimen were not performed. Therefore, the uncertainty in the length and diameter of each specimen is 
based upon the tolerances specified in the corresponding ASTM specification, with the assumption that the specified tolerance represents a two standard deviation estimate.

The final quantity in Table 5 is the bulk resistance measured by IS. Here, the value of $U$ is a "best guess" based solely on general observations. The minimum in the value of $-Z^{\prime \prime}$ is not an exact quantity. The curvature at the minimum dictates the uncertainty of the determined quantity. The interval defined by $U$ represents an overall characterization of the interval between adjacent values of $Z^{\prime}$ at the minimum of $-Z^{\prime \prime}$. Many of the adjacent values were considerably less than this quantity, but none was greater.

\subsection{Calculated Quantities}

To obtain the uncertainties of the calculated quantities requires an analysis of both measurement uncertainty and method uncertainty. The uncertainty in quantities such as the specimen conductivity are based upon standard propagation of uncertainty techniques $[42,43]$. However, the uncertainty of the total charge passed $Q_{\mathrm{T}}$ requires an additional analysis of the method uncertainty. Equation (3) is not only a means of calculating $Q_{\mathrm{T}}$, it is also a discrete approximation of the continuous function of current that varies with time. As a numerical method, trapezoidal integration has inherent uncertainty that is a function of both the time interval and the curvature of the function being integrated [44].

Since the curvature in the function of current versus time differs from specimen to specimen, a general approach was needed for the analysis of the method uncertainty. In this experiment, the current through the specimen was measured every minute. From these measurements one can perform a propagation of uncertainty calculation based upon Eq. (3) to yield a measurement uncertainty for a time interval of $1 \mathrm{~min}$. Also, one could extract every other datum, as if the current was measured every $2 \mathrm{~min}$, and perform the same uncertainty calculation. A comparison of these two results would indicate the effect of changing from a time interval of $1 \mathrm{~min}$ to a time interval of $2 \mathrm{~min}$. Fortunately, the number 360 (the number of minutes in $6 \mathrm{~h}$ ) has many possible multiplicative factors. For Sample C-2, the extraction of every $n$th datum was repeated for a number of $n$ values, the measurement uncertainty calculated, and the results plotted (see Fig. 12) with the uncertainty bars representing the expanded uncertainty $U$. Based upon these results, for measurement intervals of less than $10 \mathrm{~min}$, there appears to be no significant method uncertainty contribution to the overall uncertainty.

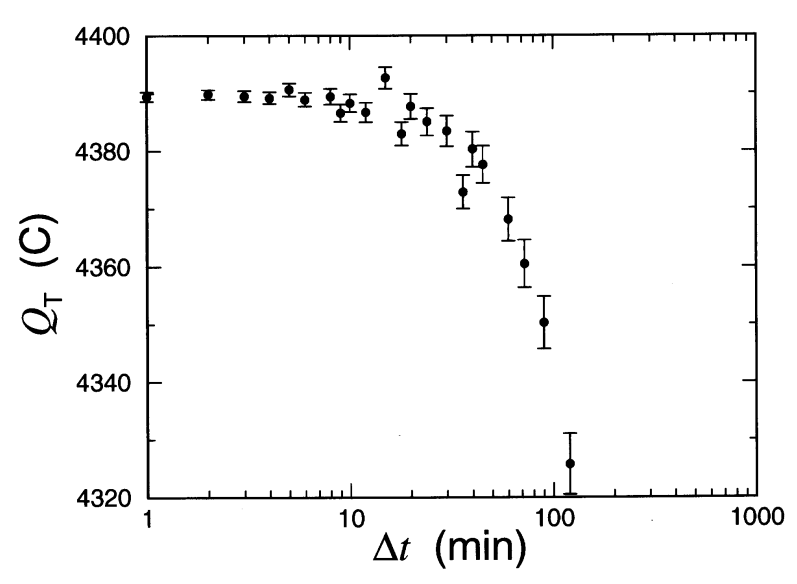

Fig. 12. Calculated total charge passed $Q_{\mathrm{T}}$ through specimen C-2 as a function of the time increment $\Delta t$ between current measurements. The error bars indicate the measurement uncertainty and the variation in the expected values (solid circles) indicate the method uncertainty.

\section{Acknowledgments}

The authors would like to thank Professor Thomas Mason (Northwestern University) and Dr. Neal Berke (W. R. Grace Company) for useful discussions. The authors would also like to thank W. R. Grace Company for providing equipment and materials for this experiment, and Frank Davis of the Building and Fire Research Laboratory for preparing the specimens.

\section{References}

[1] G. E. Monfore, The electrical resistivity of concrete, J. PCA 10, 35-48 (1968).

[2] H. W. Whittington, J. McCarter, and M. C. Forde, The conduction of electricity through concrete, Mag. Concr. Res. 33, 48-60 (1981).

[3] I. L. H. Hansson and C. M. Hansson, Electrical resistivity measurements of portland cement based materials, Cem. Concr. Res. 13, 675-683 (1983).

[4] A. Atkinson and A. K. Nickerson, The diffusion of ions through water-saturated cement, J. Mater. Sci. 19, 3068-3078 (1984).

[5] B. B. Hope, A. K. Ip, and D. G. Manning, Corrosion and electrical impedance in concrete, Cem. Concr. Res. 15, 525-534 (1985).

[6] N. Banthia, S. Djeridane, and M. Pigeon, Electrical resistivity of carbon and steel micro-fiber reinforced cements, Cem. Concr. Res. 22, 804-814 (1992).

[7] S. Feliu, C. Andrade, J. A. González, and C. Alonso, A new method for in-situ measurement of electrical resistivity of reinforced concrete, Mater. Struct. 29, 362-365 (1996).

[8] D. Buerchler, B. Elsener, and H. Boehni, Electrical resistivity and dielectric properties of hardened cement paste and mortarMat. Res. Soc. Proc. 411, Electrically Based Microstructural Characterization, R. A. Gerhardt, S. R. Taylor, and E. J. Garboczi, eds., Materials Research Society (1996) pp. 407-412.

[9] J. O'M. Bockris and A. K. N. Reddy, Modern Electrochemistry (Vol. 1), Plenum Press (1970). 
[10] R. Mills and V. M. M. Lobo, Self-Diffusion in Electrolyte Solutions, Elsevier, New York (1989).

[11] Handbook of Instrumental Techniques for Analytical Chemistry, F. A. Settle, ed., Prentice Hall (1997) pp. 760-761.

[12] D. Sohn and T. O. Mason, Electrically-induced microstructural changes in portland cement paste, 7, 81-88 (1998) Adv. Cem. Based Mater.

[13] N. R. Buenfeld and J. B. Newman, Examination of three methods for studying ion diffusion in cement pastes, mortars, and concrete, Mater. Struct. 20, 3-10 (1987).

[14] C. Andrade, M. A. Sanjuán, A. Recuero, and O. Rio, Calculation of chloride diffusivity in concrete from migration experiments, in non-steady-state conditions, Cem. Concr. Res. 24, 1214-1228 (1994).

[15] P. E. Streicher and M. G. Alexander, A chloride conduction test for concrete, Cem. Concr. Res. 25, 1284-1294 (1995).

[16] M. Scali, D. Chin, and N. S. Berke, Effect of microsilica and fly ash upon the microstructure and permeability of concrete-Proceedings of the Ninth International Conference on Cement Microscopy, International Cement Microscopy Association (1987) pp. $375-397$.

[17] C. M. Hansson and N. S. Berke, Chlorides in concrete- Mat. Res. Soc. Proc. 137, Pore Structure and Permeability of Cementitious Materials, L. R. Roberts and J. P. Skalny, eds., Materials Research Society (1989) pp. 253-270.

[18] N. S. Berke and L. R. Roberts, Use of concrete admixtures to provide long-term durability from steel corrosion-ACI SP-119, Superplasticizers and Other Chemical Admixtures in Concrete, V. M. Malhotra, ed., American Concrete Institute (1989) pp. 383-403.

[19] N. S. Berke and M. C. Hicks, Estimating the life cycle of reinforced concrete decks and marine piles using laboratory diffusion and corrosion data-ASTM STP 1137, Corrosion Forms and Control for Infrastructure, V. Chaker, ed., American Society for Testing and Materials (1992) pp. 207-231.

[20] R. F. Feldman, G. W. Chan, R. J. Brousseau, and P. J. Tumidajski, Investigation of the rapid chloride permeability test, ACI Mater. J. 91, 246-255 (1994).

[21] R. F. Feldman, L. R. Prudencia Jr., G. Chan, Rapid chloride permeability test on blended cement and other concretes: Correlations between charge, initial current and conductivity, Constr. Bldg. Mater. 13, 149-154 (1999).

[22] C. Andrade and D. Whiting, A comparison of chloride ion diffusion coefficients derived from concentration gradients and nonsteady state accelerated ionic migration, Mater. Struct. 29, 476484 (1996).

[23] N. S. Berke, Corrosion rates of steel in concrete, ASTM Standardization News, March 1986, pp. 57-61.

[24] J. R. Macdonald, Impedance Spectroscopy, John Wiley \& Sons, New York (1987).

[25] W. J. McCarter and R. Brousseau, The ac response of hardened cement paste, Cem. Concr. Res. 20, 891-900 (1990).

[26] P. Horowitz and W. Hill, The Art of Electronics, Cambridge University Press (1980).

[27] C. A. Scuderi, T. O. Mason, and H. M. Jennings, Impedance spectra of hydrating cement pastes, J. Mater. Sci. 26, 349-353 (1991).

[28] B. J. Christensen, R. T. Coverdale, R. A. Olson, S. J. Ford, E. J. Garboczi, H. M. Jennings, and T. O. Mason, Impedance spectroscopy of hydrating cement-based materials: Measurement, interpretation, and application, J. Am. Ceram. Soc. 77, 27892804 (1994).

[29] CRC Handbook of Chemistry and Physics, (Indexed by Concentrative properties of aqueous solutions), 63rd Edition, R. C. Weast, ed., CRC Press (1982).
[30] N. Carino, L. Knab, and J. Clifton, Applicability of the maturity method to high-performance concrete, NISTIR 4819, National Institute of Standards and Technology, Gaithersburg, MD, 1992.

[31] W. B. Fuller and S. Thompson, The laws of proportioning concrete, Trans. ASCE 59, 67-143 (1907).

[32] M. R. Hansen, M. L. Leming, P. Zia, and S. Ahmad, Chloride permeability and ac impedance of high performance concreteACI SP-140, High Performance Concrete in Severe Environments, P. Zia, ed., American Concrete Institute (1993) pp. 121145.

[33] R. S. Barneyback, Jr. and S. Diamond, Expression and analysis of pore fluids from hardened cement pastes and mortars, Cem. Concr. Res. 11, 279-285 (1981).

[34] P. F. McGrath and R. D. Hooton, Influence of voltage on chloride diffusion coefficients from chloride migration tests, Cem. Concr. Res. 26, 1239-1244 (1996).

[35] T. Sugiyama, Y. Tsuji, Theodore W. Bremner, and C. Hashimoto, Determination of chloride diffusion coefficient of highperformance concrete by electrical potential technique-ACI SP-163, Concrete in Marine Environment, V. M. Malhotra, ed., American Concrete Institute (1996) pp. 339-354.

[36] P. Wong, The statistical physics of sedimentary rock, Phys. Today 41 (12), 24-32 (1988).

[37] L. M. Schwartz and J. R. Banavar, Transport properties of disordered continuum systems, Phys. Rev. B 39, 11965-11970 (1989).

[38] E. J. Garboczi and D. P. Bentz, Computer simulation of the diffusivity of cement-based materials, J. Mater. Sci. 27, 20832092 (1992)

[39] J. D. Shane, T. O. Mason, H. M. Jennings, E. J. Garboczi, and D. P. Bentz, Conductivity of the interfacial transition zone in portland cement mortars, to be submitted for publication.

[40] T. J. Zhao, Z. H. Zhou, J. Q. Zhu, and N. Q. Feng, An alternating test method for concrete permeability, Cem. Concr. Res. 28, 7-12 (1998).

[41] Guide to the Expression of Uncertainty in Measurements, International Organization for Standardization (ISO), (ISBN 92-6710188-9), 1993 (Corrected and reprinted 1995).

[42] B. N. Taylor and C. E. Kuyatt, Guidelines for Evaluating and Expressing the Uncertainty of NIST Measurement Results, NIST Technical Note 1297, National Institute of Standards and Technology, Gaithersburg, MD, September 1994.

[43] E. B. Wilson, Jr., An Introduction to Scientific Research, McGraw-Hill Book Company (1952).

[44] C. F. Gerald and P. O. Wheatley, Applied Numerical Analysis, Addison-Wesley Publishing Company (1984).

About the authors: K. A. Snyder, C. Ferraris, and N. S. Martys are physicists in the Inorganic Building Materials Group in the NIST Building and Fire Research Laboratory. They study processing, degradation, and transport in the field of building materials research. E. J. Garboczi is a physicist and Leader of the Inorganic Building Materials Group. He is interested in the computational materials science of random porous materials in general, and of concrete in particular. The National Institute of Standards and Technology is an agency of the Technology Administration, U.S. Department of Commerce. 